\title{
Fragmentación socioterritorial producida por la actividad turística en Bahías de Huatulco, Oaxaca
}

Recibido: 26/05/2015 · Aceptado: 10/08/2015

\author{
Yasmin Haidé Andraca Valdés* \\ Instituto de Turismo \\ Universidad del Mar, Campus Huatulco
}

\section{Resumen}

Este trabajo analiza la relación entre la actividad turística y la fragmentación socioterritorial en Bahías de Huatulco, Oaxaca, tomando como eje estructurador los supuestos que sobre la segunda elaboran Harvey, Enríquez y Prevôt, quienes la definen como la ruptura o separación de la sociedad en el territorio, como resultado de una reestructuración productiva. Para identificar los niveles de fragmentación en el destino turístico se utilizó un índice básico que engloba indicadores de ingreso, empleo y características de la vivienda, y se emplearon variables complementarias que participan en la configuración socioterritorial, como medios de transporte, consumo de bienes y servicios, y accesibilidad. El Censo de Población y Vivienda 2010 del Instituto Nacional de Estadística y Geografía, junto con recorridos de campo realizados del 3 de agosto al 6 de noviembre de 2014, representó la fuente fundamental para la construcción de los niveles de fragmentación socioterritorial. La heterogeneidad, la división del territorio y la sociedad que resultan de las actividades turísticas se concretan en cinco niveles de fragmentación que revelan que una parte de la población es favorecida con mejores servicios y equipamiento porque se integra directamente al proceso de acumulación de capital asociado a la actividad turística y ocupa puestos gerenciales en empresas de capital internacional.

Palabras clave: Actividad turística, bienes y servicios, consumo, fragmentación socioterritorial, niveles de fragmentación

*Correo electrónico: yasty29@hotmail.com

TeORIa y PraXis · ISSN 18701582 · nÚM. 20 · JULIO-DICIEMBRE 2016 · pp. 9-36 


\title{
Socioterritorial fragmentation generated by tourism activities in Bahías de Huatulco, Oaxaca
}

\author{
Yasmin Haidé Andraca Valdés* \\ Instituto de Turismo \\ Universidad del Mar, Campus Huatulco
}

\begin{abstract}
This article analyzes the relationship between tourism activities and socio-territorial fragmentation in Bahías de Huatulco, Oaxaca, based on the proposals of Harvey, Enríquez and Prevôt about socio-territorial fragmentation which they define as the separation of society in the area as a result of productive restructuring. To identify the levels of fragmentation a basic index that includes indicators such as income, employment and housing characteristics. Additional complementary variables that participate in the socio-territorial configuration such as transportation means, consumption of consumer goods, services and accessibility were used. The 2010 Census of Population and Housing (INEGI 2010) in conjunction with field work carried out between August 3rd. and November 6th., 2014, represented the fundamental sources for the construction of socio-territorial fragmentation levels. Heterogeneity, division of territory and society caused by tourism activities are manifested in five levels of fragmentation that reveal that a part of the population is favored with better services and equipment because they are incorporated directly into the cycle of capital accumulation of tourism and hold managerial positions in companies of international capital.
\end{abstract}

KEY WoRDs: Tourism activity, goods and services, consumption, socioterritorial fragmentation, fragmentation levels.

*E-mail: yasty29@hotmail.com 


\section{Introducción}

El impulso de los destinos turísticos en zonas costeras se debe principalmente a intereses económicos, los cuales, por medio de un rápido y progresivo desarrollo urbano de los espacios receptores, buscan la obtención de utilidades; en este sentido, la estancia y el desplazamiento tienen una relación directa con el territorio al consumir recursos de este como agua, suelo y paisaje, de forma que al representar el territorio el soporte o escenario de la práctica turística se ve a su vez afectado en términos económicos, sociales y medioambientales (López, 2013).

En palabras de Pearce (1988), y de la Organización Mundial del Turismo (омт, 1990), la actividad turística incide en la calidad ambiental y paisajística, en el nivel natural y urbanístico de los destinos turísticos, lo que deriva en una problemática que involucra elementos espaciales y sociales, como dotación de servicios, concentración de equipamiento, marginación y pauperización de las zonas y de quienes las habitan, sobre todo aquellas alejadas de los atractivos turísticos y que no cuentan con las características naturales para ser explotadas turísticamente.

En ese sentido, los cambios más notorios en los destinos turísticos de sol y playa se refieren a la conversión de los usos del suelo, el rápido crecimiento demográfico y urbano, la fractura en el paisaje urbano, y la separación y exclusión de la población de acuerdo a la participación en la actividad económica (Enríquez, 2008a). Por lo tanto, el reconocimiento de esta problemática, conocida como fragmentación socioterritorial, representa el interés primordial de la presente investigación, que gira en torno a demostrar que la estructura socioeconómica y territorial de Bahías de Huatulco tiende hacia un proceso fragmentario vinculado con la actividad turística. De tal manera, tomando como eje teórico el concepto de fragmentación, el cual se abordará en el apartado siguiente, se pretende exponer la existencia de una separación de la sociedad y del territorio, a partir de múltiples estratos sociales.

Entonces, se parte del hecho de que los destinos con elementos de sol y playa, como el caso de Bahías de Huatulco, están sujetos a la planeación gubernamental, la cual promueve la transformación del espacio y la sociedad debido al crecimiento acelerado de la urbanización y cambios en los usos de suelo, donde a la par surgen procesos de precarización de las condiciones de vida para algunos residentes, dando pie a la fragmentación. 
Asimismo, en este documento se plantea que Bahías de Huatulco se caracteriza por la complejidad en la forma en que las personas participan del consumo de bienes y servicios. Por tanto, mediante el factor consumo se sustentan los argumentos que llevan a pensar en la existencia de la fragmentación socioterritorial, pues según reconoce Prévôt (2000), la fragmentación es un fenómeno que incide tanto en lo social como en lo territorial.

Por otro lado, se asocia el término de fragmentación con el de acumulación de capital, el cual ha sido reconocido como un elemento estructural que explica la razón de ser de la fragmentación, y con base en las ideas de Harvey (1992), Prévôt (2000), Valdés (1999) y Rodríguez (2013) se enmarca una nueva lectura sobre la interpretación de este fenómeno y de cómo se organiza y divide el territorio, a partir de indicadores que no solamente ven en la producción la raíz del fenómeno de la fragmentación social, sino también en el consumo de bienes y servicios.

Dicho de otra manera, en esta investigación se asume la existencia de una relación de causalidad entre los cambios registrados en la economía regida por el modelo capitalista y las formas espaciales previstas por un modelo turístico, reflejadas en el proceso de acumulación de capital, dinámica que también involucra a las sociedades que participan en la configuración del espacio. De ahí que la fragmentación socioterritorial esté vinculada con el modo en que se dividen los procesos de acceso a los bienes y servicios en Bahías de Huatulco.

Además de estudiar la fragmentación socioterritorial en Bahías de Huatulco, se busca identificar los fragmentos en los que este se divide, para representar los estratos sociales y su forma diferencial de inserción al proceso de acumulación de capital, ya que, de acuerdo con Harvey (1992), la separación y exclusión de una sociedad que se atomiza en múltiples segmentos se debe a la manera en que esta se produce y reproduce dentro del capitalismo, que a su vez cuenta con un soporte espacial que se ve convertido en una mercancía y posee un mercado. Es decir, la actividad turística del destino permea la producción social del territorio, debido a que la división social del trabajo está en la raíz del ciclo de acumulación de capital, donde se parte este proceso, y la forma en que se articulan los sujetos a las distintas escalas del proceso se ha atomizado, dividido y creado una sociedad de fragmentos. 
El trabajo tuvo como objetivo general analizar la relación entre la actividad turística y la fragmentación social y territorial en Bahías de Huatulco. La selección de esta zona alude a su característica como proyecto turístico regido por la acumulación de capital, que tiende a evidenciar las disparidades en cuanto al consumo de bienes y servicios.

Dado que los estudios acerca de la fragmentación socioterritorial en contextos turísticos son escasos, destacan los realizados por Prieto (2008), Velázquez y Gómez (2005) en Argentina, Alvarado (2012) en México y Chile, y Enríquez (2008a), quienes han abordado el concepto de fragmentación tanto de manera descriptiva como interpretativa asociada a los cambios económicos mundiales. Esta investigación no solo buscará describir un fenómeno sino también explicarlo, mediante la utilización de indicadores socioeconómicos (ingreso, acceso a bienes y servicios) que permitirán concretar los siguientes objetivos específicos: explicar la fragmentación y su relación con las actividades turísticas, a través de un marco analítico vinculado con conceptos y categorías que lo soporten desde un enfoque crítico; construir indicadores con base en el ingreso y consumo de bienes y servicios, para reconocer los niveles de fragmentación en los que se encuentra dividido el destino, y, por último, dar cuenta de los niveles de fragmentación de Bahías de Huatulco en función de la actividad turística y la acumulación de capital.

\section{Fragmentación socioterritorial, actividad turística y ciclo de acumulación de capital}

El turismo como actividad económica crea y se apropia de espacios mediante tres ejes, el social, el geográfico y el natural, que resulta en la reestructuración del espacio adaptado a las condiciones estructurales necesarias para su reproducción (Castro y López, 2010). En este sentido, el capitalismo en cuanto modelo de desarrollo económico adoptado por las actividades económicas regidas por la acumulación de capital acelera la transformación de los espacios.

Siguiendo esta línea, el turismo, visto desde el ciclo de acumulación, posee un carácter inmobiliario, que produce y modifica espacios, con influencia en las estructuras económicas, sociales, políticas, culturales y ambientales de los países, ya que el turismo crea o transforma espacios recreacionales y de confort 
que tienen como fin motivar el consumo de bienes y servicios para obtener ganancias (García, 2000).

Por lo tanto, entender el turismo desde su dimensión espacial implica reconocer el impacto en la estructuración del espacio, derivada de las actividades turísticas. Es por ello que toda actividad enfocada a este fenómeno "tiene una inscripción en el espacio, pero no en un espacio banal, sino en un espacio producido que interactúa en forma dialéctica con las actividades humanas" (Rodríguez, 2007, p. 124).

Entonces, la distribución socioterritorial asociada a los destinos turísticos, en específico de sol y playa, se basa en el turismo de masas; es decir, ubican los servicios turísticos cerca de los atractivos para incrementar utilidades y mercantilizar el espacio enfocado a la captación de turistas con ingresos altos para el consumo de bienes y servicios. Generalmente ese espacio está alejado del conglomerado urbano que habitan los locales (Mantero, Barbini y Bertoni, 1999).

Al respecto, Judd (2003) y Pérez (2010) sostienen que la actividad turística genera espacios fragmentados, con una diferenciación espacial interior, donde por lo común las zonas hoteleras y comerciales cuentan con condiciones infraestructurales y de acceso a servicios superiores a las de la población local. En este sentido, los destinos turísticos tienen una conformación espacial policéntrica por la dispersión de los atractivos que marca la participación desigual de la población local y de los turistas en el proceso de acumulación de capital.

Por tanto, al hablar de turismo en espacios de sol y playa se hace referencia directa a la urbanización turística, que incorpora equipamientos turísticos paralelos a las playas y la construcción de zonas habitacionales en áreas periféricas, haciendo un elevado uso del suelo para empleo turístico y los servicios complementarios que aseguren la accesibilidad turística del destino (Barros de Moraes, 2013; Benseny, 2006).

De tal forma, el territorio costero turístico produce transformaciones sociales, económicas y territoriales a partir de la implementación de actividades turísticas que relegan las tradicionales, acelera la urbanización y la reconfiguración del espacio que dinamiza la economía (Vera, 1997). Es precisamente este interés económico el que representa el motor de los destinos turísticos y hace que se dejen de lado aspectos ambientales, paisajísticos y sociales.

Aparejado a esta dinámica, basada en la modificación del territorio en beneficio de paisajes artificiales, rápido crecimiento urbano y demográfico, suceden 
el incremento de flujos migratorios y la ampliación de la mancha urbana, lo que origina la fragmentación social y territorial, entendida como la desarticulación de la estructura urbana del destino en múltiples unidades, que da paso a la creación de espacios segregados (Enríquez, 2008b). Es decir, a pesar de que los destinos de sol y playa son un factor para el desarrollo económico de los países, su implantación conlleva transformaciones en la sociedad y en el territorio receptor, y da pie a fenómenos como la fragmentación, la segregación y la exclusión.

Dentro de la literatura sobre fragmentación, los cambios en la estructura urbana en conjunto con el funcionamiento institucional y las relaciones sociales al interior de las ciudades por la adopción de la economía capitalista han sido abordados por Link (2008), Salinas (2009), Prévôt (2000) y Longhi, Bolsi, Paolasso, Velázquez y Celemín (2013), dando prioridad a la relación entre la acumulación de capital y la fragmentación socioterritorial, relación que precisamente fundamenta el presente trabajo y que permite ubicarla en el enfoque micro de la fragmentación, asociada a la ruptura, división y separación social en la ciudad, vinculadas con reestructuraciones productivas y cambios en el estado de trabajo.

Entonces, la fragmentación enfocada a los procesos de división del espacio y la sociedad lleva el nombre de socioterritorial, la cual involucra una complejidad entre diversos estratos sociales; no es una simple consecuencia de las desigualdades socioeconómicas, sino el resultado de la diferenciación social en el espacio, lo que se manifiesta en la distribución de los grupos sociales en el territorio (Veiga, 2004, 2008).

Por ende, la fragmentación socioterritorial es vista como un elemento modificador de espacios, al mismo tiempo que como ejemplo de una política de crecimiento basada en priorizar la integración selectiva de la gente al proceso de trabajo que demandan las empresas, puesto que estas son las que imponen la lógica de incorporación de las personas a diferentes procesos de consumo de bienes y servicios, a través de la actividad económica predominante (Alvarado, 2012; Alvarado y Di Castro, 2011).

El punto de partida para asumir la existencia de la fragmentación procede de la categoría "acumulación de capital", la cual es reconocida por Rodríguez (2013), Tapia (2001) y Andraca (2007) como un elemento estructural que 
conlleva la separación y exclusión de múltiples sectores de una sociedad que se atomizan y dividen de acuerdo a sus distintas escalas de participación en el proceso de acumulación.

La acumulación de capital se entiende como el circuito integrado por tres fases, que comienzan desde la programación, organización y producción de bienes, base de la producción de plusvalor, seguido por un segundo momento, previsto en la distribución y circulación de bienes y servicios, y que finaliza con la realización del capital, lo cual significa e involucra al consumo de lo socialmente producido y su colocación en un mercado (De la Peña, 1987). Por ello, según lo definido en este párrafo, la acumulación es un proceso general que empieza desde la producción concreta de mercancías, que involucra una relación capital-trabajo, lo cual lleva implícita la explotación del trabajador y genera una forma de distribución y consumo de bienes.

En cuanto al consumo de bienes, "sin producción no hay consumo, pero sin consumo no hay producción...” (Marx, 1984, p. 291), lo cual significa que la acumulación es un proceso articulado de diferentes fases, donde se pone mayor énfasis en la parte final del mismo, el consumo, porque este se encuentra ligado al ingreso de las personas.

Por tanto, la acumulación se relaciona con las transformaciones del capital a través de distintos ciclos de producción; es decir, comienza cuando el capitalista decide invertir " $\mathrm{x}$ " cantidad en materia prima, maquinaria, pagos de salarios y diversas erogaciones que le ayudan a producir mercancías y al final le originan ganancias. Posteriormente se lleva a cabo la venta de las mercancías que asegura la ganancia de una cantidad mayor a la invertida y entonces el capitalista decide si reinvierte el total o parte de las ganancias, para seguir con el ciclo de producción o, de lo contrario, interrumpirlo. De tal manera, el capital invertido crece y se acumula vinculándose con el siguiente ciclo de producción (De la Peña, 1987).

Al reconocer el papel transformador de la acumulación de capital en el nivel mundial, se resalta el rol que esta juega para la creación y transformación de ciudades diversas, en donde no importan las consecuencias ecológicas, sociales 0 políticas que se deriven, siempre y cuando exista un crecimiento económico, y, por ende, al explicar la fragmentación a través de la acumulación de capital se puede observar la forma en que esta modifica el espacio (Harvey, 2003). 
Como puede advertirse, en el proceso de acumulación de capital reside la diferenciación social y lo heterogéneo de un determinado territorio. El estudio de la acumulación muestra la importancia del capital para los seres humanos, ya que debido a este la sociedad puede adquirir bienes y servicios para mantener su vida cotidiana, y con ello permitirle ubicarse en espacios donde exista población con similares características socioeconómicas. Es decir, la utilización del capital para el consumo de diversos bienes y servicios contribuirá a evidenciar la fragmentación de un espacio específico.

En síntesis, para estudiar la fragmentación, lo que interesa del ciclo de acumulación de capital es la manera en que desarrolla desarticulaciones en territorios y sociedades, y asimismo ver la posición que ocupa el individuo dentro del proceso de acumulación para determinar su forma de apropiación de lo socialmente producido, ya que al vincular la acumulación de capital con la fragmentación se alude a lo que Rodríguez (2013) denomina la transformación y/o reestructuración de territorios fragmentados tanto social como espacialmente.

Concretamente en destinos de sol y playa el turismo en su vertiente económica induce a la construcción de soportes para la producción, la distribución y el consumo, desvelando cambios en la cobertura de infraestructura y en la distribución del equipamiento (Hiernaux, 1989).

Britton (1991) afirma que la actividad turística es una vía que permite llevar a cabo la reproducción de la acumulación de capital, y que es mediante la intervención del Estado como esta se reproduce y fortalece, ya que genera utilidades y los Estados se ven en la necesidad de crear empleos y transformar o desarrollar espacios que estarán incorporados al proceso de acumulación de capital.

Desde el mismo punto de vista, Harvey (1992) menciona que la construcción de condiciones materiales es menester para dar pie a la producción, circulación y acumulación capitalista. Entonces, a fin de que el turismo tenga lugar dentro de la panorámica capitalista, el Estado debe construir los medios necesarios para la realización del capital, siendo el destino turístico el punto focal para la localización de la inversión extranjera por su facilidad de generar ganancias.

Así, para que un destino turístico entre al eje de acumulación requiere de préstamos dirigidos a la construcción de infraestructura de acceso y servicios, reglas para la apropiación del territorio, funcionalización del espacio para la instalación de la oferta turística y la eliminación de barreras que impiden 
la accesibilidad al destino (Palafox, 2013). Es por ello que el turismo se ha convertido en medio importante para llevar a cabo la acumulación de capital, debido a su carácter generador de ganancias. Por tanto, el Estado ha intervenido en la creación de elementos estructurales que hacen posible la producción, circulación y acumulación capitalista, y de esta forma se evidencia la fragmentación socioterritorial en destinos turísticos.

\section{Contextualización de la zona de estudio}

Bahías de Huatulco se sitúa en la costa sur del Pacífico mexicano en el municipio de Santa María Huatulco, distrito de Pochutla del estado de Oaxaca, en las estribaciones de la Sierra Madre del Sur, al sur de la república mexicana (Fondo Nacional de Fomento al Turismo [Fonatur], 1982). De acuerdo con la Carpeta Básica de Información, el centro integralmente planeado (СIP) es una franja que abarca aproximadamente 35 kilómetros de longitud y siete kilómetros de ancho, que limita al norte con la carretera Acapulco-Salina Cruz, al sur con el océano Pacífico, al oriente con el río Copalita y al poniente con los Bajos de Coyula. Se localiza a 765 kilómetros de la Ciudad de México, a 277 kilómetros de la ciudad de Oaxaca, a 145 kilómetros de Puerto Escondido y a 29 kilómetros de su cabecera municipal, Santa María Huatulco (Fonatur, 1982).

El CIP Huatulco abarca una superficie de 20975 hectáreas, que corresponde al polígono expropiado por el Fonatur, el cual está integrado por la zona de Bahías de Huatulco que funge como el centro turístico-urbano del destino; el Parque Nacional Huatulco, área destinada para la conservación de la flora y fauna de la región, y, por último, la zona de Bajos, dedicada a las actividades agropecuarias, la cual actualmente se encuentra en problemas comunales.

Las características fisiográficas de Huatulco favorecen las actividades turísticas: en la zona de Bajos predominan terrenos planos, ríos, áreas de montañas y agrícolas, mientras que la zona de Bahías de Huatulco se conforma por nueve bahías y 36 playas, valles estrechos con terrenos en pendientes y grandes áreas de montañas (Fonatur, 2010). Esta última es la zona de estudio, dado que concentra los sectores del desarrollo urbano, inmobiliario residencial turístico y hotelero (véase figura 1). La zona de Bahías de Huatulco está configurada por tres polígonos: La Crucecita, integrada por 19 sectores; Santa Cruz, por cuatro sectores, y Tangolunda, por seis. 

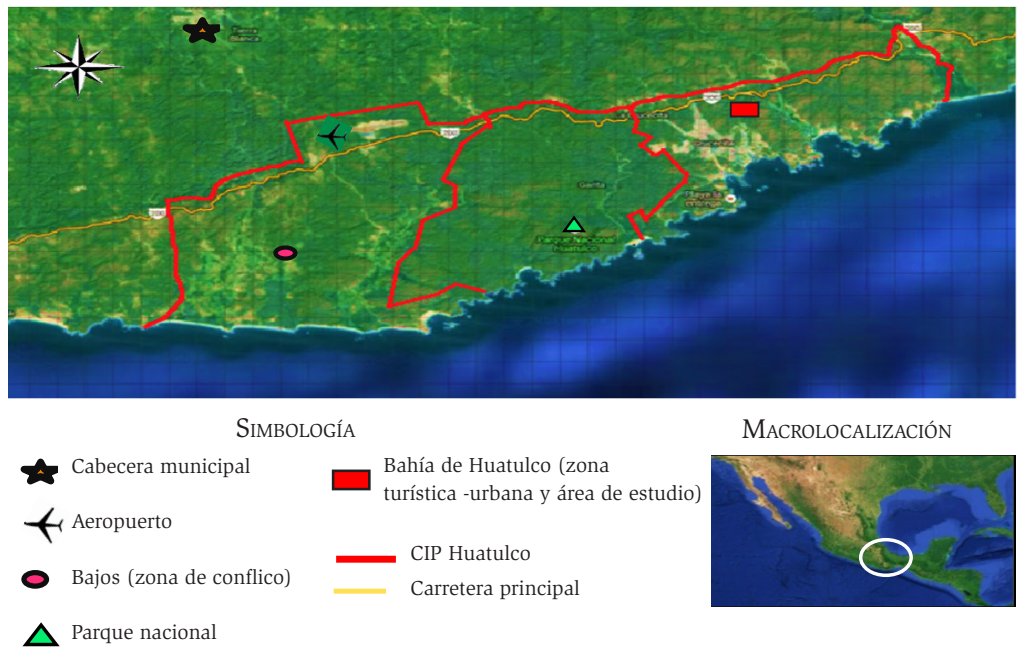

Fuente: Elaboración propia con base digital Globe, 2014.

FiguRa 1. Localización del CIP Huatulco

\section{Metodología}

En esta investigación, el eje analítico empleado para desvelar la relación entre la fragmentación socioterritorial y la actividad turística en Bahías de Huatulco es la propuesta teórica de fragmentación socioterritorial, abordada a través de Harvey, Enríquez, Prévôt y De la Peña, quienes la asocian con la ruptura o división y separación social del territorio derivada de reestructuraciones productivas.

Se toman como base estos autores vinculados con la visión dialéctica, porque se busca encontrar las consecuencias de la exclusión de ciertos sectores de la población, lo cual se evidencia mediante los niveles de fragmentación socioterritorial de la zona turística de Bahías de Huatulco, demostrando así la existencia de fenómenos económicos y sociales y las contradicciones propias del modelo de producción capitalista.

A su vez, se emplea este enfoque porque permite trabajar con racionalidad, objetividad y sistematicidad en el descubrimiento de las características del capitalismo (Vargas, 2006). De igual manera, además de reconocer la existencia de la fragmentación socioterritorial, destaca los acontecimientos que la originan, 
los cuales son resultado de las relaciones sociales que establecen los individuos en el proceso de producción y que dan lugar a la estratificación de la sociedad, para este caso, estructuradas a partir de la actividad turística.

Asimismo, la investigación fue de tipo estática y mantuvo un enfoque predominantemente cuantitativo en torno al fenómeno de la fragmentación socioterritorial, dando mayor peso a los factores económicos para su medición y después vincularla con la actividad turística de Bahías de Huatulco.

En cuanto a las técnicas cualitativas, se recurrió a la observación directa, realizada del 3 de agosto al 6 de noviembre de 2014. Mediante las fichas de observación se recopiló información complementaria sobre el comportamiento de los habitantes en relación con categorías de características de la vivienda, accesibilidad, medios de transporte y servicios públicos, ya que en los sectores con presencia de conjuntos residenciales de ingresos altos el acceso fue denegado, específicamente en Residencial Conejos, Tangolunda Residencial Campo de Golf y Residencial Arrocito.

Las bases de datos representaron el pilar de la investigación, por lo que el uso de fuentes secundarias provenientes del Censo de Población y Vivienda del Instituto Nacional de Estadística y Geografía (INEGI, 2000 y 2010) ayudó a complementar la información obtenida en las encuestas aplicadas del 3 de agosto al 6 de noviembre de 2014 en los 29 sectores que integran Bahías de Huatulco, con el propósito de extraer datos de carácter socioeconómico y agruparlos, para conformar así cinco niveles de fragmentación socioterritorial.

A fin de determinar el número de encuestas, el tipo de muestreo aplicado fue el estratificado por asignación proporcional, el cual consistió en distribuir proporcionalmente el tamaño de muestra de cada localidad, es decir, a mayor tamaño de la localidad le corresponde un mayor número de encuestas y viceversa.

Por tanto, de acuerdo al total contabilizado de casas habitación (5 364) en los 29 sectores distribuidos en tres polígonos -La Crucecita (5 214), Santa Cruz (89) y Tangolunda (61)-, se estimó el tamaño de muestra de cada localidad mediante la siguiente fórmula (Ibarra, 1998):

\section{$\frac{\text { (total de encuestas por localidad) (\% del total de casas habitación del sector) }}{100}$}

Posteriormente, se prosiguió con la aplicación de las 397 encuestas resultantes, donde los aspectos a medir fueron cuestiones socioeconómicas y turísticas, 
para después agrupar los resultados en cinco niveles socioeconómicos (bajo, medio bajo, medio, medio alto y alto), que representan los niveles de fragmentación de Bahías de Huatulco.

\section{Resultados y discusión}

Después de la aplicación de las encuestas y con los datos arrojados, se procedió a la estructuración y caracterización de los cinco niveles de fragmentación de Bahías de Huatulco. A partir de estos niveles se clasificaron los 29 sectores que lo conforman, y entre los resultados obtenidos se destacan indicadores relacionados con el consumo de bienes, el ingreso, las características de la vivienda y la conectividad (véase cuadro 1 y figura 2).

\section{CUADRo 1. Características de los niveles de fragmentación de Bahías de Huatulco}

\begin{tabular}{|c|c|c|c|}
\hline $\begin{array}{c}\text { Nivel/ } \\
\text { característica }\end{array}$ & $\begin{array}{l}\text { Distribución del } \\
\quad \text { ingreso }\end{array}$ & $\begin{array}{c}\text { Características de la } \\
\text { vivienda }\end{array}$ & $\begin{array}{c}\text { Uso de medios de } \\
\text { transporte y consumo } \\
\text { de bienes }\end{array}$ \\
\hline $\begin{array}{l}\text { Bajo } \\
\text { Sectores: H3 }\end{array}$ & $\begin{array}{l}\text { En este nivel existe } \\
\text { un predominio de ha- } \\
\text { bitantes que perciben } \\
\text { menos de un salario } \\
\text { mínimo }(75 \%) \text {. Un } \\
\text { porcentaje menor de } \\
\text { población que gana } \\
\text { de uno a dos salarios } \\
\text { mínimos }(25 \%) \text {. }\end{array}$ & $\begin{array}{l}\text { * Las viviendas } \\
\text { propias representan } \\
65 \% \text { y } 35 \% \text { las } \\
\text { rentadas, donde la } \\
\text { mayor parte de las } \\
\text { paredes y techos son } \\
\text { de lámina ( } 40 \% \text { ), } \\
\text { madera ( } 34 \% \text { ) y una } \\
\text { menor proporción de } \\
\text { concreto. } \\
\text { * } 80 \% \text { de las casas } \\
\text { cuentan con al menos } \\
\text { una o dos habitacio- } \\
\text { nes. } \\
\text { * } 28 \% \text { de las vivien- } \\
\text { das tiene un baño } \\
\text { completo y } 72 \% \text { un } \\
\text { medio baño. }\end{array}$ & $\begin{array}{l}\text { * } 96 \% \text { de los habi- } \\
\text { tantes de este nivel se } \\
\text { desplazan en trans- } \\
\text { porte público. } \\
\text { * El grueso consumo } \\
\text { de bienes se centra en } \\
\text { televisor, refrigerador } \\
\text { y celular ( } 48 \% \text { ). } \\
\text { * Mientras que el con- } \\
\text { sumo de bienes como } \\
\text { el modular, lavadora } \\
\text { y línea telefónica } \\
\text { alcanza } 24 \% \text {. } \\
\text { * En cuanto al horno } \\
\text { de microondas y } \\
\text { el internet, no son } \\
\text { bienes consumidos en } \\
\text { el sector bajo. }\end{array}$ \\
\hline
\end{tabular}




\section{Cuadro 1. Características de los niveles de fragmentación de Bahías de Huatulco \\ (continúa)}

\begin{tabular}{|c|c|c|c|}
\hline $\begin{array}{c}\text { Nivel/ } \\
\text { característica }\end{array}$ & $\begin{array}{l}\text { Distribución del } \\
\text { ingreso }\end{array}$ & $\begin{array}{c}\text { Características de la } \\
\text { vivienda }\end{array}$ & $\begin{array}{c}\text { Uso de medios de } \\
\text { transporte y consumo } \\
\text { de bienes }\end{array}$ \\
\hline $\begin{array}{l}\text { Medio bajo } \\
\text { Sectores: U2 } \\
\text { Norte y } \\
\text { Vicente } \\
\text { Guerrero }\end{array}$ & $\begin{array}{l}\text { Predominio de habi- } \\
\text { tantes que perciben } \\
\text { de uno a dos salarios } \\
\text { mínimos }(65 \%) \text {. Un } \\
\text { menor porcentaje de } \\
\text { la población que gana } \\
\text { de dos a cinco salarios } \\
\text { mínimos ( } 25 \%) \text { y, } \\
\text { por último, un escaso } \\
\text { porcentaje de perso- } \\
\text { nas con ingresos de } \\
\text { menos de un salario } \\
\text { mínimo }(10 \%) \text {. }\end{array}$ & $\begin{array}{l}\text { * La mayoría de las } \\
\text { viviendas son propias } \\
76 \% \text { y } 24 \% \text { rentadas, } \\
\text { los techos y paredes } \\
\text { son de lámina ( } 30 \%) \text {, } \\
\text { madera }(25 \%) \text { y } \\
\text { concreto ( } 45 \%) \\
\text { * } 78 \% \text { de las vivien- } \\
\text { das cuenta con tres } \\
\text { habitaciones. } \\
\text { * } 80 \% \text { de las vivien- } \\
\text { das cuenta con un } \\
\text { baño completo y } 20 \% \\
\text { con un medio baño. }\end{array}$ & $\begin{array}{l}\text { * En estos hogares } \\
\text { uno de cada cuatro } \\
\text { hogares posee auto- } \\
\text { móvil propio, por lo } \\
\text { que la mayoría utiliza } \\
\text { el transporte público } \\
\text { para desplazarse. } \\
{ }^{*} \text { Bienes como el re- } \\
\text { frigerador, el celular y } \\
\text { el televisor son consu- } \\
\text { midos en } 62 \% \text {. } \\
{ }^{*} \text { El consumo de } \\
\text { modular y lavadora } \\
\text { alcanza } 38 \% \text {. } \\
{ }^{*} \text { La línea telefónica y } \\
\text { el internet son consu- } \\
\text { midos por } 21 \% \text { de la } \\
\text { población. }\end{array}$ \\
\hline $\begin{array}{l}\text { Medio } \\
\text { Sectores: U2 } \\
\text { Sur, U2, Cocoa, } \\
\text { J, T, S, V, H, H2, } \\
\text { Ampliación J y } \\
\text { La Bocana de } \\
\text { Copalita }\end{array}$ & $\begin{array}{l}\text { Predominio de habi- } \\
\text { tantes que cuentan } \\
\text { con un ingreso de dos } \\
\text { hasta cinco salarios } \\
\text { mínimos ( } 65 \% \text { ). Así } \\
\text { como } 20 \% \text { de pobla- } \\
\text { ción con ingresos de } \\
\text { uno a dos salarios } \\
\text { mínimos y una escasa } \\
\text { porción de } 15 \% \text { de } \\
\text { personas que ganan } \\
\text { de cinco a diez sala- } \\
\text { rios mínimos. }\end{array}$ & $\begin{array}{l}* 58 \% \text { de las vivien- } \\
\text { das son rentadas y } \\
42 \% \text { son propias, de } \\
\text { las cuales } 80 \% \text { están } \\
\text { construidas de mate- } \\
\text { riales sólidos como } \\
\text { concreto, y una escasa } \\
\text { parte de lámina y ma- } \\
\text { dera. Algunos de los } \\
\text { edificios de intereses } \\
\text { social se encuentran } \\
\text { deteriorados. } \\
* 85 \% \text { cuentan con } \\
\text { entre tres y cuatro } \\
\text { habitaciones. }\end{array}$ & $\begin{array}{l}\text { * } 40 \% \text { de las familias } \\
\text { cuentan con un auto- } \\
\text { móvil. } \\
\text { * } 60 \% \text { de la po- } \\
\text { blación tiene una } \\
\text { motocicleta. } \\
\text { * En el sector medio } \\
\text { el consumo de celular, } \\
\text { televisor, refrigerador, } \\
\text { modular y lavadora } \\
\text { alcanza } 71 \text { \%. } \\
\text { * El internet, horno } \\
\text { de microondas y la } \\
\text { línea telefónica son } \\
\text { consumidos por } 38 \text { \% } \\
\text { de la población. }\end{array}$ \\
\hline
\end{tabular}




\section{Cuadro 1. Características de los niveles de fragmentación de Bahías de Huatulco \\ (continúa)}

\begin{tabular}{|c|c|c|c|}
\hline $\begin{array}{c}\text { Nivel/ } \\
\text { característica }\end{array}$ & $\begin{array}{l}\text { Distribución del } \\
\text { ingreso }\end{array}$ & $\begin{array}{c}\text { Características de la } \\
\text { vivienda }\end{array}$ & $\begin{array}{c}\text { Uso de medios de } \\
\text { transporte y consumo } \\
\text { de bienes }\end{array}$ \\
\hline $\begin{array}{l}\text { Medio } \\
\text { Sectores: U2 } \\
\text { Sur, U2, Cocoa, } \\
\text { J, T, S, V, H, H2, } \\
\text { Ampliación J y } \\
\text { La Bocana de } \\
\text { Copalita }\end{array}$ & & $\begin{array}{l}{ }^{*} \text { Todas las viviendas } \\
\text { cuentan con un baño } \\
\text { completo } \\
* 60 \% \text { de las vi- } \\
\text { viendas tiene línea } \\
\text { telefónica. } \\
{ }^{*} \text { Es común encontrar } \\
\text { en este nivel zonas de } \\
\text { esparcimiento/recrea- } \\
\text { ción como parques y } \\
\text { canchas deportivas. }\end{array}$ & \\
\hline $\begin{array}{l}\text { Medio alto } \\
\text { Sectores: A, F, } \\
\text { Balcones de } \\
\text { Tangolunda, K, } \\
\text { I y L }\end{array}$ & $\begin{array}{l}\text { Predominio de } \\
\text { habitantes que gana } \\
\text { de cinco a diez } \\
\text { salarios mínimos } \\
(53 \%) \text {. Así como } \\
25 \% \text { de población } \\
\text { que percibe más de } \\
\text { diez salarios mínimos, } \\
15 \% \text { percibe de } \\
\text { dos a cinco salarios } \\
\text { mínimos y, por } \\
\text { último, un menor } \\
\text { porcentaje gana de } \\
\text { uno a dos salarios } \\
\text { mínimos (7 \%). }\end{array}$ & $\begin{array}{l}\text { * } 70 \% \text { de las } \\
\text { viviendas son propias } \\
\text { y } 30 \% \text { son rentadas; } \\
\text { están construidas de } \\
\text { materiales sólidos } \\
\text { (concreto). } \\
\text { * } 80 \% \text { de las } \\
\text { viviendas cuenta con } \\
\text { cinco habitaciones y } \\
20 \% \text { con seis. } \\
\text { * } 10 \% \text { de las } \\
\text { viviendas cuenta con } \\
\text { tres baños completos } \\
\text { y el resto con dos. } \\
\text { * } 85 \% \text { de las } \\
\text { viviendas tiene línea } \\
\text { telefónica. } \\
\text { * En este nivel } \\
\text { hay zonas de } \\
\text { esparcimiento/ } \\
\text { recreación como } \\
\text { clubes deportivos. }\end{array}$ & $\begin{array}{l}* 60 \% \text { de las familias } \\
\text { cuenta con un } \\
\text { automóvil y } 40 \% \text { con } \\
\text { dos. } \\
{ }^{*} \text { El porcentaje de } \\
\text { la población que } \\
\text { consume bienes como } \\
\text { modular, televisor, } \\
\text { lavadora, refrigerador, } \\
\text { horno de microondas, } \\
\text { celular e internet } \\
\text { representa } 82 \% \text {. } \\
\text { *Mientras que la línea } \\
\text { telefónica solo es } \\
\text { consumida por } 63 \% \\
\text { de la población. }\end{array}$ \\
\hline
\end{tabular}




\section{CuAdro 1. Características de los niveles de fragmentación de Bahías de Huatulco \\ (finaliza)}

\begin{tabular}{|c|c|c|c|}
\hline $\begin{array}{c}\text { Nivel/ } \\
\text { característica }\end{array}$ & $\begin{array}{l}\text { Distribución del } \\
\quad \text { ingreso }\end{array}$ & $\begin{array}{c}\text { Características de la } \\
\text { vivienda }\end{array}$ & $\begin{array}{c}\text { Uso de medios de } \\
\text { transporte y consumo } \\
\text { de bienes }\end{array}$ \\
\hline $\begin{array}{l}\text { Alto } \\
\text { Sectores: M, } \\
\text { O, P,C, E, } \\
\text { Tangolunda, } \\
\text { Residencial } \\
\text { Campo de } \\
\text { Golf, Arrocito } \\
\text { y Residencial } \\
\text { Conejos }\end{array}$ & $\begin{array}{l}\text { En este nivel existe } \\
\text { un predominio } \\
\text { de habitantes que } \\
\text { perciben más de diez } \\
\text { salarios mínimos } \\
(80 \%) \text {. Un porcentaje } \\
\text { menor de población } \\
\text { que gana de cinco } \\
\text { a diez salarios } \\
\text { mínimos (15\%) y } \\
\text { una población con } \\
\text { ingresos de dos } \\
\text { a cinco salarios } \\
\text { mínimos ( } 5 \%) \text {. La } \\
\text { principal característica } \\
\text { es que la mayoría de } \\
\text { los espacios de este } \\
\text { nivel se encuentran } \\
\text { controlados. }\end{array}$ & $\begin{array}{l}\text { * } 95 \% \text { de las } \\
\text { viviendas son } \\
\text { propias, las cuales } \\
\text { están construidas de } \\
\text { concreto. } \\
\text { * } 60 \% \text { de las } \\
\text { viviendas tiene } \\
\text { como mínimo siete } \\
\text { habitaciones, el resto } \\
\text { cuenta con más de } \\
\text { siete. } \\
\text { * } 40 \% \text { de las } \\
\text { viviendas tiene como } \\
\text { mínimo tres baños } \\
\text { completos, } 80 \% \text { tiene } \\
\text { de cuatro o más. } \\
\text { * } 95 \% \text { de las } \\
\text { viviendas cuenta } \\
\text { con línea telefónica, } \\
\text { el resto no tiene } \\
\text { por falta de } \\
\text { infraestructura de la } \\
\text { compañía que brinda } \\
\text { el servicio. } \\
\text { * En este nivel } \\
\text { hay zonas de } \\
\text { esparcimiento/ } \\
\text { recreación como } \\
\text { clubes deportivos y } \\
\text { de playa. }\end{array}$ & $\begin{array}{l}\text { * } 75 \% \text { de las } \\
\text { familias tiene dos } \\
\text { automóviles, el resto } \\
\text { cuenta con tres o } \\
\text { más. } \\
\text { * } 92 \% \text { de la } \\
\text { población cuenta con } \\
\text { modular, televisor, } \\
\text { refrigerador, lavadora, } \\
\text { horno de microondas, } \\
\text { celular e internet. }\end{array}$ \\
\hline
\end{tabular}

Fuente: Elaboración propia con base en el trabajo de campo realizado del 3 de agosto al 6 de noviembre de 2014 . 
En la figura 2 se puede apreciar la existencia de puntos donde el acceso a los servicios básicos es restringido para algunas personas, debido a su menor participación en la acumulación de capital de la actividad turística (sector H3, nivel bajo), por tanto, resulta complicado para ellos acceder al consumo de bienes y servicios como automóvil, computadora, línea telefónica, internet, entre otros.

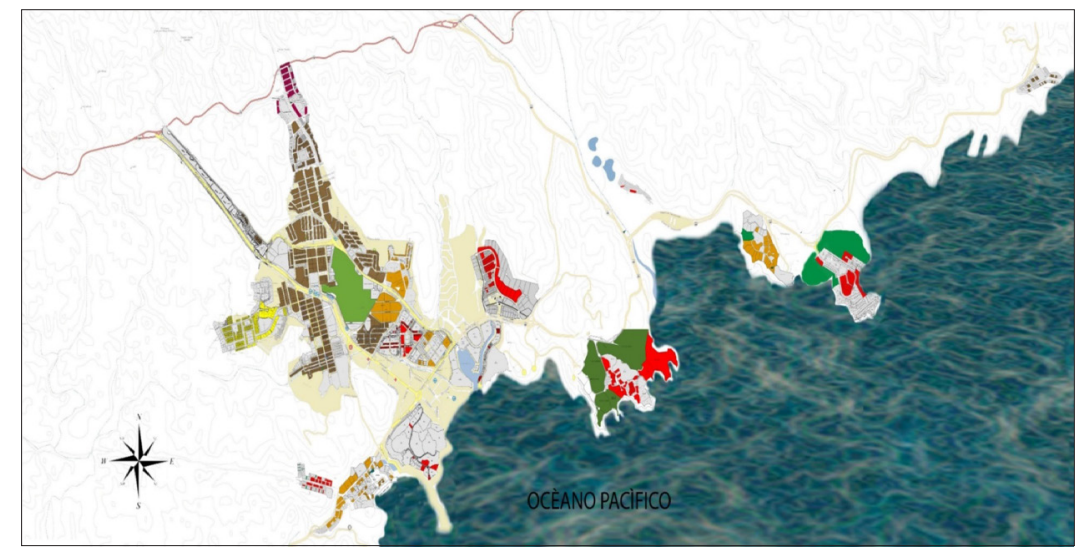

Simbología Nivel Socioeconómico Polígono nivel alto

Límites _ Polígono nivel medio alto Polígono nivel medio

Ríos y lagos $\sim$ Polígono nivel medio bajo

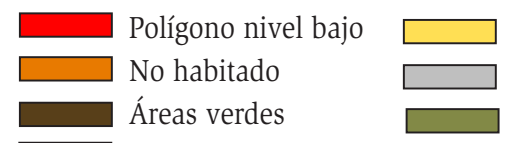

Escala numérica y gráfica

$1: 172 \mathrm{~m}$.
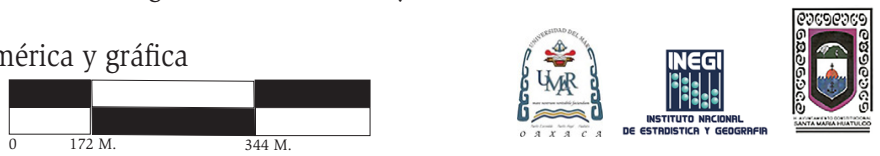

Fuente: Municipio de Santa María Huatulco.

Elaboración: Daniel Alberto Cruz Méndez con datos de Ana Laura Nazario Méndez

FIGURA 2. Niveles de fragmentación socioterritorial en Bahías de Huatulco, Oaxaca

A su vez, se identificaron sectores que presentan características contrarias debido a su grado de participación en la acumulación de capital, los cuales tienen mayor consumo de bienes y servicios y se ubican relativamente cerca de las actividades productivas (económicas-turísticas). En su mayoría estos sectores 
están integrados por población cuya capacidad adquisitiva es alta, como se observa principalmente en Santa Cruz y Tangolunda (nivel medio alto y alto, sectores A, F, K, L, I, M, O, P, C, E, Balcones de Tangolunda, Tangolunda Residencial Campo de Golf, Arrocito y Residencial Conejos).

Siguiendo en esta línea, se argumenta que los sectores con mayor participación en la lógica de producción capitalista del nivel alto y medio alto son considerados como espacios integrados a la globalización por el hecho de tener población cuyo empleo se encuentra incluido en la actividad económica predominante (turismo, en empresas de capital internacional como gerentes y dueños), y que al mismo tiempo les permite un mayor acceso al consumo de bienes y servicios (véase cuadro 1), lo cual evidencia que en la zona de Bahías de Huatulco existen diversas realidades, es decir, no todos los sectores cuentan con las mismas posibilidades de acceder a bienes y servicios. Este hecho se traduce en la fragmentación con manifestaciones tanto sociales como espaciales.

De tal manera, la trasformación del territorio mediante la implantación de infraestructura y servicios regidos por la fuerza laboral desvela que en Bahías de Huatulco se da una concentración de capital, la cual es promovida en parte por la inversión de diversas empresas que buscan obtener utilidades mediante la instauración de establecimientos, principalmente de índole turístico. Esto hace que las instituciones encargadas del desarrollo del turismo en la zona (Fonatur) den prioridad a estas compañías para apropiarse del espacio y así realizar sus actividades dentro del marco de producción capitalista. Por tanto, con base en los argumentos de Harvey (1992), en el marco del modo de producción capitalista, la actividad turística en Bahías ha constituido un elemento para la modificación del territorio, donde se crean las condiciones necesarias para la producción, circulación y acumulación de capital.

Entonces, la implementación de la actividad turística regida por el proceso de acumulación de capital ha hecho que aquella se desarrolle en mayor medida en espacios que sean funcionales para llevar a cabo la reproducción del capital, es por ello que polígonos como Santa Cruz, Tangolunda y ciertos sectores de La Crucecita $(\mathrm{H}, \mathrm{H} 2)$ cuentan con mayor infraestructura y equipamiento, exacerbando la diferenciación social. En palabras de Harvey (1992), todos aquellos espacios vistos desde los procesos de acumulación de capital derivarán en la diferenciación social y lo heterogéneo. Así, Bahías de Huatulco es un espacio 
dividido donde coexisten distintos estratos sociales (véase figura 2). Por tanto, se observa cómo cada uno de ellos se inserta de manera diferencial al proceso de acumulación de capital, lo que conlleva que presenten diversas características socioeconómicas y, por ende, el grado de consumo de bienes y servicios sea distinto para cada estrato, donde unos tienen mayor facilidad para consumir (véase cuadro 1).

De igual modo, Marx (1984) explicaba esta situación a partir del problema del modelo capitalista, que no permite el acceso al proceso de acumulación a la mayoría de la gente, puesto que unos cuantos elegidos son los que invierten, toman las decisiones y disponen las tecnologías que regulan la vida, mientras que otros se ven en la necesidad de desplegarse de la creatividad humana.

Por otro lado, retomando el papel que juegan las autoridades encargadas del turismo, en palabras de Palafox (2013), las instituciones que velan por el desarrollo del turismo en un espacio son importantes para la realización de la acumulación, ya que por medio de ellas se dota de las condiciones estructurales necesarias para reproducir y mantener el proceso de capital. En Bahías de Huatulco, Fonatur es el organismo encargado de la consolidación de la acumulación, al constituir el principal elemento que lleva a la modificación del espacio, pues busca dotar de condiciones estructurales para la llegada de capitales nacionales y principalmente extranjeros.

Asimismo, el arribo de capitales nacionales y extranjeros al destino también contribuye a la realización del proceso de acumulación, dado que estos son los que transforman los recursos en servicios, después los ponen en circulación, y finalizan con la realización del capital. Ello significa e involucra el consumo de lo socialmente producido y su colocación en un mercado, asegurando la obtención de una cantidad mayor a la antes invertida y motivando a los entes económicos a invertir y acumular la ganancia lograda, lo que, en palabras de Marx (1984), se conoce como ciclo de acumulación de capital.

Por tanto, Bahías de Huatulco, al ser un destino turístico regido por la acumulación de capital, presenta características y procesos tanto económicos como sociales que sirven de base para la reproducción de la fragmentación. Una manifestación de la fragmentación se observa en la concentración de equipamiento y dotación de infraestructura (urbano-turística) desigual, mayoritariamente en 
sectores (sector A, E, F, H, H2, L y Tangolunda) que cuentan con las características para la reproducción del capital y la obtención de mejores ganancias para los capitalistas, por lo que a la par se crean espacios que están fuera de la lógica del capital porque no cuentan con potencial para el desarrollo de actividades turísticas y son destinados a alojar a la fuerza de trabajo, como los sectores H3, I, J, U2 y U2-Norte.

Finalmente, retomando a Benseny (2006), se reafirma la idea de que los destinos de sol y playa ostentan un uso extensivo del territorio, debido a los elementos edificados e infraestructurales necesarios para albergar las actividades turísticas y la fuerza de trabajo, siendo la concentración de infraestructura y la dotación desigual de servicios y de equipamiento turístico y complementario factores que inciden en la separación de la sociedad en estratos sociales con diferente grado de participación en el proceso de acumulación de capital.

\section{Consideraciones finales}

Después de analizar los resultados de la investigación, se concluye que Bahías de Huatulco es una zona que evidencia heterogeneidad y división en su territorio y sociedad, debido a la implementación de actividades turísticas regidas por la acumulación de capital, las cuales han traído consigo la transformación de los usos de suelo, crecimiento demográfico, ampliación de lo urbano con tintes rurales, precarización social para algunos sectores apartados del enclave turístico, problemas con el acceso de bienes y servicios, entre otros, lo que ha hecho de la zona turística un espacio fragmentado, donde una parte de la población es favorecida con mejores servicios y equipamientos y el acceso a mayor bienes, dado que se integra de manera más activa al proceso de acumulación.

En años recientes, el turismo y sus diversas actividades han sido relevantes para la economía del destino, por lo que mediante la creación de políticas públicas estatales y nacionales, así como la intervención privada, se ha orientado a Bahías de Huatulco a constituir un espacio dirigido principalmente hacia el consumo, donde el carácter económico ha impactado en la construcción de sistemas de transportación, la captación de divisas, la generación de empleos, la industria de la construcción, así como en la penetración de diversas transnacionales, que han hecho de Bahías una zona incorporada a la globalización. 
Aunado a lo anterior, es indudable que el turismo, en su connotación económica, indujo a la zona a la construcción de soportes para la producción, circulación y acumulación de capital, lo cual ha originado transformaciones que derivan en la división del espacio y la sociedad, lo que se evidencia a través de los cinco niveles de fragmentación identificados (nivel bajo, medio bajo, medio, medio alto y alto).

Por otro lado, la derrama económica y la creciente oferta de empleos ligados al turismo han ocasionado en la zona de Bahías de Huatulco un aumento de su población y a su vez el crecimiento de la mancha urbana, aunque no de la forma planeada desde la fundación del cIP; las autoridades encargadas del turismo han tenido que ajustar las estrategias de desarrollo para promover el crecimiento del cip, favoreciendo la ampliación de infraestructura y la construcción de equipamientos en los sectores habitados por los niveles medio alto y alto.

Así pues, ante la adopción de la actividad turística, la institución encargada del turismo (Fonatur) ha enfocado las estrategias de desarrollo hacia la organización y jerarquización del territorio de acuerdo a los intereses económicos, dando prioridad a aquellos espacios que sean más funcionales para la acumulación de capital (Tangolunda, Balcones de Tangolunda, Arrocito, Residencial Campo de Golf, A, E y O), creando una zona fragmentada donde surgen a la luz las diferencias socioeconómicas de los diversos estratos sociales que integran Bahías de Huatulco, mismas que se aprecian en los cinco niveles de fragmentación encontrados.

Entonces, a pesar de la reformulación de estrategias para promover el desarrollo del cip, en la zona de Bahías se observa la existencia de espacios donde el acceso a servicios es restringido para algunos estratos sociales, debido a la forma en que se insertan a la acumulación de capital, por tanto, es complicado para ellos acceder al consumo de bienes y servicios como automóvil, computadora, servicio telefónico, internet, por mencionar algunos, razón por la cual se ven en la necesidad de buscar espacios donde tengan posibilidad de acceder. De tal suerte, el territorio se reestructura para incluir ciertos agregados sociales y excluir a otros dando paso a la división social y espacial del sitio.

De igual manera, es importante señalar que el tipo de turismo que está recibiendo el cIP Huatulco, turismo masivo, no necesariamente ha tenido un efecto positivo, ya que la zona de Bahías presenta diferencias en cuanto al abastecimiento de servicios públicos, donde se da prioridad a los sectores con ingresos 
superiores (sector A, C, E, F, O, Tangolunda Residencial Campo de Golf, Arrocito y Residencial Conejos).

Por tanto, Bahías de Huatulco constituye una zona turística regida por la acumulación del capital, el cual requiere de condiciones estructurales para reproducir y mantener la acumulación. Así, al crear tales condiciones, se desarrollan cambios sociales y espaciales que originan un espacio fragmentado, donde las diferencias entre diversos estratos sociales salen a la luz, por el consumo desigual de bienes y servicios. De tal modo, afirmar que Bahías de Huatulco es una zona fragmentada significa inferir que algunos espacios tienen mayor consumo de bienes y servicios, mientras que el resto busca cómo insertarse al ciclo de acumulación de capital.

En cuanto a los aportes de la investigación, destacan los cinco niveles de fragmentación encontrados en Bahías de Huatulco -los cuales desvelan la separación de la sociedad y el consumo diferencial-, cada uno caracterizado por compartir elementos de la estructura social de manera uniforme, como el ingreso, el consumo, y el acceso a bienes y servicios. Entonces, conforme cada fragmento representa un nivel socioeconómico diferente, el acceso a tales elementos de la estructura social cambia, reflejando distintos grados de articulación al proceso de acumulación de capital; es decir, se instituye la validación empírica del aparato crítico, estableciendo relaciones de causalidad entre la fragmentación socioterritorial, la actividad turística y la acumulación de capital.

Las características de la actividad turística permitieron extrapolar las condiciones de la fragmentación al ámbito turístico, que si bien se clasifica como una actividad terciaria propia de lo urbano, no siempre se desarrolla en asentamientos con características urbanísticas asociadas a este. Por lo tanto, utilizando las propuestas de Enríquez (2008a), se pudieron sentar las bases para el análisis de la fragmentación en espacios turísticos de sol y playa desde un enfoque crítico.

En este sentido, la articulación al proceso de acumulación de capital se justifica a partir del tipo de empleo. La actividad turística, al ser la actividad básica del destino, incide en la forma en que la población participa en la economía; de acuerdo con el involucramiento de cada persona en el desarrollo de actividades ligadas al turismo se define el ingreso, de modo que, en el nivel bajo, el empleo de la población se concentra en actividades de tipo primario (agricultura y pesca), y en menor medida en actividades terciarias (vendedores ambulantes), es 
decir, la totalidad de empleos son complementarios o diferentes de la actividad base, lo que determina su casi nula articulación al proceso de acumulación.

Para el nivel medio bajo, entre los empleos predominantes se destacan los puestos de cajeros, empleados de mostrador, acarreadores, vendedores ambulantes y trabajadores de la construcción, lo que implica que los empleos también son complementarios a la actividad turística, vinculando a la población al proceso de articulación de capital de manera marginal.

A su vez, el nivel medio presenta una estructura de empleos relacionados con el trabajo de oficina, la docencia, el comercio formal (empleados) y la prestación de servicios turísticos. Por lo tanto, su inserción al proceso de acumulación es más directa y se visualiza por medio de las características del consumo de ese sector, con mayor acceso a bienes y servicios, dada la rentabilidad de la actividad turística.

La participación de la población en el proceso de articulación de capital en el nivel medio alto está ligada a la actividad turística a través de empleos relativos a la prestación de servicios turísticos, puestos administrativos, gerenciales, vinculados a instituciones de salud, el comercio formal (jefes), la docencia, o bien, directores de instituciones educativas. Por consiguiente, las características del consumo son diferentes del resto de los niveles, ya que para esta población resulta redituable trabajar en el desarrollo de actividades turísticas.

Por último, el sector alto cuenta con la población que participa más directa y activamente en la acumulación de capital, ya que los empleos predominantes se asocian a prestadores de servicios turísticos, puestos administrativos y gerenciales, relacionados con la salud y el comercio formal (dueños), en este caso, la mayoría son dueños de los medios de producción, tanto básicos como complementarios, posición que les da ventaja sobre el resto de los niveles.

Este proceso de fragmentación transforma a Bahías de Huatulco en un espacio urbano con periferias pauperizadas, en el cual se exponen las áreas separadas del ciclo productivo del capital, y su distinción de las áreas residenciales de prestigio y las nuevas urbanizaciones, con diferencias en cuanto a calidad y disponibilidad del consumo y la recreación. Aunado a ello, se observan espacios donde el acceso a los servicios básicos es restringido para algunas personas, debido a su forma de participación en el proceso de acumulación, por lo que les es complicado acceder al consumo de bienes y servicios (automóvil, computadora, línea telefónica, internet, etc.). Por tanto, si se pretende alcanzar un 
desarrollo homogéneo de la zona turística, es necesario reducir las diferencias socioeconómicas entre sectores.

Finalmente, la zona turística Bahías de Huatulco se ha definido por la tercerización de su economía y de sus actividades productivas, vinculadas sobre todo al turismo. Pero el porcentaje de participación no es el mismo en La Crucecita, Santa Cruz y Tangolunda. Los sectores ubicados en los niveles medio, medio alto y alto son aquellos que tienen mayor cantidad de población ocupada en actividades turísticas, contrastando con el nivel bajo, el cual presenta la menor participación al dedicarse principalmente a actividades diferentes de la básica, o complementarias, lo que justifica la división socioterritorial de Bahías de Huatulco.

\section{Fuentes consultadas}

Alvarado, C. (2012). Fragmentación y segregación socioterritorial en México y Chile. México: Juan Pablos Editor/Universidad Autónoma del Estado de Morelos.

Alvarado, C. y Di Castro, M. (2011). Un acercamiento al fenómeno de la fragmentación socioterritorial en la zona noreste y noroeste de la ciudad de Cuernavaca, Morelos. Revista Geográfica de América Central, 2, 1-15. Recuperado de www.observatoriogeograficoamericalatina.org. $\mathrm{mx} /$ ega113/geografiaeconomica/geografiaurbana/028.pdf [2015, 10 de agosto]

Andraca, Y. (2007). Fragmentación de la Zona Metropolitana de la Ciudad de Toluca. Análisis de indicadores de cinco municipios. Páramo del Campo y la Ciudad, 12(5), 130-148.

Barros de Moraes, L. (2013). Impactos del turismo de sol y playa en el litoral sur de Sergipe, Brasil. Estudios y Perspectivas en Turismo, 22(3), 526-545. Recuperado de http://www.scielo.org.ar/scielo.php?script = sci_ arttext\&pid = S1851-17322013000300008 [2014, 3 de marzo].

Benseny, G. (2006). El espacio turístico litoral. Aportes y Transferencias, 10(2), 102122. Recuperado de http://www.redalyc.org/pdf/276/27610208. pdf [2014, 17 de febrero]. 
Britton, S. (1991). Tourism, capital, and place: towards a critical geography of tourism. Environment and Planning D. Society and Space, 9(4), 451-478. Retrieved from http://www.researchgate.net/journal/0263-7758_ Environment_and_Planning_D_Society_and_Space [2013, October $\left.2^{\text {nd }}\right]$.

Castro, U. y López, J. (septiembre, 2010). Desarrollo regional y turismo: Revisión histórico estructural de la Riviera Nayarit, México. TURyDES, 3(8), 1-16. Recuperado de http://www.eumed.net/rev/turydes/08/ calc.htm [2013, 5 de diciembre].

Enríquez, J. (2008a). Las nuevas ciudades para el turismo. Caso Puerto Peñasco, Sonora, México. Scripta Nova, 12(91), 1-21. Recuperado de http://www.ub.edu/geocrit/sn/sn-270/sn-270-91.htm [2013, 18 de abril].

Enríquez, J. (2008b). Segregación y fragmentación en las nuevas ciudades para el turismo. Caso Puerto Peñasco, Sonora, México. Revista de Arquitectura, Urbanismo y Ciencias Sociales, 1(1), 1-32. Recuperado de http:// dialnet.unirioja.es/servlet/autor? codigo $=1964837$ [2014, 24 de enero].

Fondo Nacional de Fomento al Turismo (Fonatur). (1982). Plan Maestro Turístico de Bahías de Huatulco, Oaxaca. México: Autor.

Fondo Nacional de Fomento al Turismo (Fonatur). (2010). Fonatur, 35 años única historia narrada por sus fundadores y protagonistas. México: Autor. García, E. (2000). Los espacios turísticos del litoral Andaluz. Cuadernos Geográficos, 30, 43-76. Recuperado de http://www.juntadeandalucia. es/educacion/vscripts/wbi/w/rec/1505.pdf [2014, 4 de julio].

Harvey, D. (1992). El capitalismo: la fábrica de la fragmentación. Vuelta, 190, 23-25.

Harvey, D. (2003). Espacios de esperanza. Madrid: Akal.

Hiernaux, D. (1989). Teoría y praxis del espacio turístico. México: Universidad Autónoma Metropolitana-Xochimilco.

Ibarra, O. (1998). Estadística para la administración turística. México: Diana/ Escuela de Administración Turística.

Instituto Nacional de Estadística y Geografía (INEGI). (2000). XII Censo General de Población y Vivienda. México: Autor. 
Instituto Nacional de Estadística y Geografía (INEGI). (2010). Censo de Población y Vivienda 2010. México: Autor.

Judd, D. (septiembre, 2003). El turismo urbano y la geografía de la ciudad. Revista Eure, 29(87), 51-62. Recuperado de http://www.redalyc.org/ articulo.oa?id = 19608704 [2014, 17 de mayo].

Link, F. (diciembre, 2008). De la policentralidad a la fragmentación en Santiago de Chile. Centro-h, 2, 13-24. Recuperado de http://www.redalyc. org/articulo.oa?id = 115112535002 [2014, 28 de febrero].

Longhi, F., Bolsi, A., Paolasso, P., Velázquez, G. y Celemín, P. (enerojunio, 2013). Fragmentación socioterritorial y condiciones de vida en la Argentina en los albores del siglo xxi. Revista Latinoamericana de Población, 7(12), 99-131. Recuperado de http:// www.alapop.org/2009/Revista/Articulos/relap12/relap_12_04. pdf [2015, 20 de agosto].

López, L. (2013). Impactos territoriales del turismo y lineamientos de ordenación para territorios con vocación turística. Caso de estudio municipio de Santa Fe de Antioquia, Colombia. En Social Science Research Network (SSRN). Recuperado de http:// ssrn.com/abstract $=2561543$ o http://dx.doi.org/102139/ ssrn. 2561543

Mantero, J., Barbini, B. y Bertoni, M. (1999). Turistas y residentes en destinos de sol y playa de Argentina. Gestión Turística, 4, 7-25. Recuperado de http://mingaonline.uach.cl/scielo.php?pid = S071864281999000 $100001 \&$ script $=$ sci_arttext $[2013,17$ de diciembre $]$.

Marx, K. (1984). Contribución a la crítica de la economía política ( $8^{\text {a }}$ ed.). México: Fondo de Cultura Económica.

Organización Mundial del Turismo (омт). (1990). Planificación del turismo nacional y regional. Londres: International Thompson Bussiness Press.

Palafox, A. (2013). El turismo como eje de acumulación. Revista Crítica de Ciencias Sociales y Jurídicas. Recuperado de http://www.redalyc.org/ articulo.oa?id = 18127008020 [2014, 15 de agosto] .

Pearce, D. (1988). Desarrollo turístico, su planificación y ubicación geográfica. México: Trillas. 
Peña, S. de la (1987). El modo de producción capitalista. México: Siglo XXI Editores.

Pérez, E. (2010). Segregación socioespacial en ciudades turísticas, el caso de Puerto Vallarta, México. Región y Sociedad, 22(49), 143-176. Recuperado de http://www.redalyc.org/articulo.oa?id = 10215725006 [2013, 28 de octubre].

Prévôt, M.-F. (enero-junio, 2000). Segregación, fragmentación, secesión. Hacia una nueva geografía social en la aglomeración de Buenos Aires. Economía, Sociedad y Territorio, 2(7), 405-431. Recuperado de http://www. redalyc.org/articulo.oa?id $=11100702$ [2013, 21 de noviembre].

Prieto, M. (2008). Fragmentación socioterritorial y calidad de vida urbana en bahía Blanca. Geograficando, 4(4), 193-214. Recuperado de www. memoria.fahce.unlp.edu.ar/art_revistas/pr.3746/pr.3746.pdf [2015, 23 de agosto].

Rodríguez, M. (diciembre, 2013). El patrón de acumulación neoliberal: fragmentación y exclusión socio-territorial en América Latina. Revista Electrónica de Psicología Política, 11(31), 1-21. Recuperado de http://www. psicopol.unsl.edu.ar/2013-12-Art\%EDculo\%2001.pdf [2014, 7 de febrero].

Rodríguez, S. (julio, 2007). Los espacios del turismo en el territorio del Plan Puebla Panamá. Ciencias Sociales Online 4(2), 119-138. Recuperado de http://www.uvm.cl/csonline/2007_2/pdf/rodriguez.pdf [2013, 9 de abril].

Salinas, E. (septiembre, 2009). Fragmentación urbana y su relevancia en la planificación urbana y territorial actual. Ignire-Centro de Estudio de Política Pública, 49-59.

Tapia, J. (2001). Integración sincrónica de territorios. El caso de tres comunidades que gravitan en torno a las zonas metropolitanas de las ciudades de Toluca y México. En M. Camarena Luhrs (coord.), Cultura y política en el desarrollo regional de México (pp. 72-88). El Colegio Mexiquense/ Universidad de Guadalajara.

Valdés, E. (1999). La ciudad dual y los nuevos fragmentos urbanos: Los guetos de la riqueza. Revista de Administración Pública y Sociedad, 12, 21-37. 
Vargas, G. (2006). Introducción a la teoría económica, un enfoque latinoamericano ( $2^{\mathrm{a}}$ ed.). México: Pearson.

Veiga, D. (2004). Desigualdades sociales y fragmentación urbana: obstáculos para una ciudad democrática. En El rostro urbano de América Latina (pp. 193-209). Buenos Aires: Consejo Latinoamericano de Ciencias Sociales. Recuperado de http://biblioteca.clacso.edu.ar/gsdl/ collect/clacso/index/assoc/D2496.dir/9p4art1.pdf [2014, 10 de enero].

Veiga, D. (2008). Fragmentación socioterritorial y desigualdades en el Área Metropolitana de Montevideo. Pampa, 4, 11-36. Recuperado de http://bibliotecavirtual.unl.edu.ar/ojs/index.php/PAMPA/article/ view/3150/4668 [2014, 20 de noviembre]

Velázquez, G. y Gómez, S. (2005). Medio teórico-científico-informacional y equipamiento tecnológico: Modernización y fragmentación socioterritorial en la Argentina a comienzos del siglo xxi. Cuadernos de Geografía, 14, 43-63.

Vera, F. (1997). Análisis territorial del turismo. Barcelona: Ariel Geografía. 